\title{
The quintessential quiescence of cancer stem cells: a struggle towards better treatment
}

\author{
Anuradha Vaidya \\ Symbiosis School of Biomedical Sciences, Symbiosis International University, Symbiosis Knowledge Village, Pune 412115, India. \\ Correspondence to: Dr. Anuradha Vaidya, Symbiosis School of Biomedical Sciences, Symbiosis International University, Symbiosis Knowledge \\ Village, Pune 412115, India. E-mail: dydirector@ssbs.edu.in
}

It has been almost two decades, since the existence of leukemic stem cells (LSCs) were first demonstrated in acute myeloid leukemia (AML) using xenogenic transplant models. ${ }^{[1,2]}$ Although LSCs were the first type of cancer stem cell (CSC) to be described experimentally, CSCs have been identified in a variety of malignancies and extensive efforts have been made to understand and characterize specific biomarkers associated with the various types of cancers. ${ }^{[3]}$ However, it still remains unclear whether these transformed cells arise as a result of the normal cells undergoing a malignant change or whether they are the differentiated malignant cells that have re-acquired stem-like characteristics. ${ }^{[4]}$ Irrespective of the conundrum regarding the origin of the LSCs, studies have highlighted that there exists remarkable heterogeneity to the LSC compartment at both the cellular and molecular level. ${ }^{[5]}$ Such intratumoral heterogeneity has been associated with the failure of many chemotherapeutic agents and progress to a refractory state, also known as the state of secondary resistance. ${ }^{[6]}$ Furthermore acquired quiescence has offered the CSCs to evade being killed by conventional chemotherapy and radiotherapy, leading to cancer relapse and metastasis. ${ }^{[4]}$

Cancer immune surveillance is considered to be an important host protection process to inhibit carcinogenesis and to maintain cellular homeostasis. It has been shown that deregulation of the tightly controlled immune response may result in immune escape of CSCs, and there has been a growing interest in understanding the mechanisms that regulate the immune modulatory properties of the CSCs in order to develop more effective therapy that can eradicate these quiescent cells. Some of the signs of immune tolerance projected by CSCs include downregulation of positive co-stimulatory molecules, higher expression of negative co-stimulatory molecules, and secretion of soluble factors that induce regulatory $\mathrm{T}$

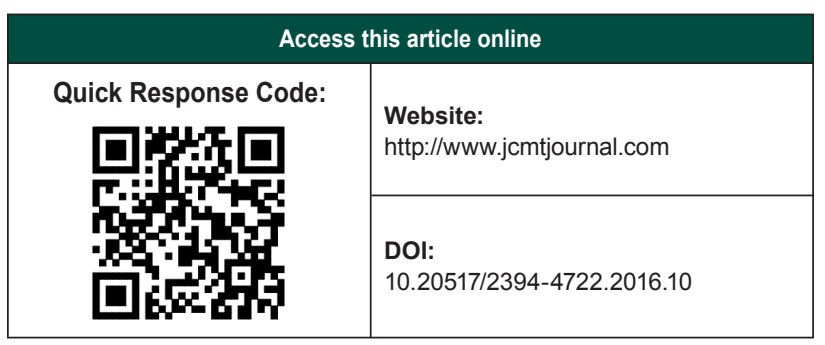

cells, such that they inhibit the productive activation of effector T cells. ${ }^{[7]}$

Other than the intrinsic factors such as the signaling pathways and the very recently stated micro RNA (miR-126) that drives quiescence and self-renewal within the LSCs; ${ }^{[8]}$ extrinsic factors such as the tumour microenvironment also plays a central role in the progression of cancer. The microenvironment has been implicated as a source of chemoresistance and disease relapse. Recent advances strongly indicate that the leukemic cells target the microenvironment to create an environment that is more suitable for the progression of cancer. ${ }^{[9]}$ In fact quiescence has been described as a survival strategy adopted by CSCs to resist harsh environmental conditions and cytotoxic insults. ${ }^{[10]}$

Thus, cancer stem cells are the "unscathed successors" that progressively deteriorate the condition of the patient. Their inherent quiescent "status quo" along with the complex interplay of several factors (as those discussed above) contribute towards sustaining and propagating the malignant disease. Eradicating CSCs, the root of cancer origin and recurrence, has therefore been thought as a promising approach to improve cancer survival or even to cure cancer patients. ${ }^{[11]}$ Nevertheless, a major challenge thwarting the eradication of CSCs is that their identification and isolation has been hampered due to the non-specificity of their cell surface biomarkers ${ }^{[3]}$ and also by the fact that the commonly used fluorescent markers are not stable, and hence do not allow tracking over an extended period of time. ${ }^{[12]}$

A study conducted by Gardane et al., ${ }^{[13]}$ published in this issue demonstrates that low concentrations of

This is an open access article distributed under the terms of the Creative Commons Attribution-NonCommercial-ShareAlike 3.0 License, which allows others to remix, tweak, and build upon the work non-commercially, as long as the author is credited and the new creations are licensed under the identical terms.

For reprints contact: service@oaepublish.com

How to cite this article: Vaidya $A$. The quintessential quiescence of cancer stem cells: a struggle towards better treatment. J Cancer Metasta Treat 2016;2:243-4

Received: 24-02-2016; Accepted: 29-03-2016. 
curcumin sensitize the quiescent leukemic cells (QLCs) towards more effective killing by the anti mitotic drug, 5-fluorouracil. Curcumin pushes the QLCs into the cell cycle, thereby sensitizing them through the induction of proliferative responses. Similar observations have been reported by other studies wherein it has been implicated that the induction of cell cycle entry of the QLCs enhances apoptosis and elimination of human primary AML cells in vivo. ${ }^{[14,15]}$ Such studies underscore the essential role of cell cycle regulation in LSC function.

\section{Financial support and sponsorship}

Nil.

\section{Conflicts of interest}

There are no conflicts of interest.

\section{REFERENCES}

1. Lapidot T, Sirard C, Vormoor J, Murdoch B, Hoang T, CaceresCortes J, Minden M, Paterson B, Caligiuri MA, Dick JE. A cell initiating acute myeloid leukaemia after transplantation into SCID mice. Nature 1994;367:645-8.

2. Bonnet D, Dick JE. Human acute myeloid leukemia is organized as a hierarchy that originates from a primitive hematopoietic cell. Nat Med 1997;3:730-7.

3. Murar M, Vaidya A. Cancer Stem Cell Markers: Premises and Prospects. Biomark Med 2015;9:1331-42.

4. Buczacki S, Davies RJ, Winton DJ. Stem cells, quiescence and rectal carcinoma: an unexplored relationship and potential therapeutic target. Br J Cancer 2011;105:1253-9.
5. Horton SJ, Huntly BJP. Recent advances in acute myeloid leukemia stem cell biology. Haematologica 2012;97:966-74.

6. Vidal SJ, Rodriguez-Bravo V, Galsky M, Cordon-Cardo C, Domingo-Domenech J. Targeting cancer stem cells to suppress acquired chemotherapy resistance. Oncogene 2014;33:4451-63.

7. Ghebeh H, Al-Alwan M. Do cancer stem cells have an immunomodulatory role different from the bulk of tumor cells? $J$ Carcinog Mutagen 2013;S14:003.

8. Raffel S, Trumpp A. miR-126 drives quiescence and self-renewal in leukemic stem cells. Cancer Cell 2016;29:133-5.

9. Bakker E, Qattan M, Mutti L, Demonacos C, Krstic-Demonacos M. The role of microenvironment and immunity in drug response in leukemia. Biochim Biophys Acta 2016;1863:414-26.

10. Ann Zeuner. The secret life of quiescent cancer stem cells. Mol Cell Oncol 2015;2:e968067.

11. Hu Y, Fu L. Targeting cancer stem cells: a new therapy to cure cancer patients. Am J Cancer Res 2012;2:340-56.

12. Lin HH, Lee HW, Lin RJ, Huang CW, Liao YC, Chen YT, Fang JM, Lee TC, Yu AL, Chang HC. Tracking and finding slow-proliferating/ quiescent cancer stem cells with fluorescent nanodiamonds. Small 2015;11:4394-402.

13. Gardane A, Poonawala M, Vaidya A. Curcumin sensitizes quiescent leukemic cells to anti-mitotic drug 5-fluorouracil by inducing proliferative responses in them. $J$ Cancer Metasta Treat 2016;2:24552.

14. Vaidya AA, Sharma MB, Kale VP. Suppression of p38-stress kinase sensitizes quiescent leukemic cells to anti-mitotic drugs by inducing proliferative responses in them. Cancer Biol Ther 2008;7:1232-40.

15. Saito Y, Uchida N, Tanaka S, Suzuki N, Tomizawa-Murasawa M, Sone A, Najima Y, Takagi S, Aoki Y, Wake A, Taniguchi S, Shultz $\mathrm{LD}$, Ishikawa $\mathrm{F}$. Induction of cell cycle entry eliminates human leukemia stem cells in a mouse model of AML. Nat Biotechnol 2010;28:275-80. 